\title{
Conhecimento farmacológico e etnobotânico de alunos do primeiro ano do ensino médio, numa escola pública do Município de João Pessoa, Paraíba
}

\section{Gibran Anderson Oliveira da Silva}

Universidade Federal da Paraíba. Centro de Ciências Exatas e da Natueza. Curso de Licenciatura em Ciências Biológicas. Campus I. João Pessoa-PB. Brasil. (CEP 58051-900). E-mail: gibranderson@gmail.com.

Resumo. A presente pesquisa consiste em uma aula dinâmica e uma análise sobre informações de espécies vegetais presentes na literatura científica e possivelmente utilizadas por estudantes no tratamento de doenças. Objetivando identificar e integrar o conhecimento popular e científico de estudantes do primeiro ano do Ensino Médio sobre quatorze espécies de plantas e suas propriedades farmacológicas: Alliums sativum (alho), Cinnamomum cassia (canela), Cymbopogon citratus (capim-santo), Cocos nucifera (сосо), Coffea arabica (café), Daucus carota (cenoura), Lippia sp. (erva-cidreira), Matricaria chamomilla (camomila), Mentha piperita (hortelã), Ocimum basilicum (manjericão), Olea europaea (azeitona), Origanum vulgare (orégano), Saccharum sp. (cana-de-açúcar) e Zingiber officinale (gengibre). Foram obtidos 19 publicações científicas e as informações sintetizadas foram utilizadas para elaboração de questionários préteste, aplicados anterior a execução de uma aula dinâmica, e pós-teste. Os alunos demonstraram conhecer todas as plantas como medicinais tanto no pré-teste, em percentual baixo, quanto no pós-teste. Em sua maioria os alunos conhecem mais de uma planta medicinal e as informações sobre as plantas foram obtidas verbalmente através de familiares (58\%), professores (58\%), agentes de saúde (41\%) e amigos (21\%). A forma de utilização dessas plantas foi majoritariamente através de chás (93\%), consumo (43\%) e inalação (21\%), para o tratamento de gripe (86\%), febre $(71 \%)$, inflamações (57\%), dor de cabeça (50\%), ferimentos e insônia (43\%). Certamente, as 14 espécies mencionadas fazem parte do contexto sócio-histórico e cultural dos estudantes do primeiro ano do Ensino Médio de um colégio em João Pessoa, e foram utilizadas como fitoterápicos através de informações obtidas particularmente através do conhecimento popular pela transmissão verbal da informação para combater diversos sintomas. Também se pode enfatizar que o uso da aula dinâmica e do método foi eficaz tanto para interação e diálogo entre aluno-aluno e aluno-professor quanto no aumento da compreensão dos estudantes.

Palavras-chave: Educação ambiental; Plantas medicinais; Educação formal; Etnobotânica.

Abstract. Pharmacological and ethnobotanical knowledge of first year middle school students, in a public school in the Municipality
Recebido:

$17 / 11 / 2017$

Aceito:

27/12/2017

Publicado:

$31 / 12 / 2017$

Acesso aberto

Artigo completo

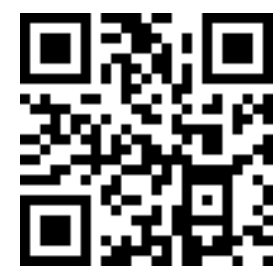

ORCID

(D) 0000-0001-8451-2123

Gibran Anderson

Oliveira da Silva 
of João Pessoa, Paraíba. The present research consists of a dynamic class and an analysis about information of vegetal species present in the scientific literature and possibly used by students in the treatment of diseases. Aiming to identify and integrate the popular and scientific knowledge of first year high school students about fourteen species of plants and their pharmacological properties: Alliums sativum (garlic), Cinnamomum cassia (cinnamon), Cymbopogon citratus (holy grass), Cocos nucifera (coconut), Coffea arabica (coffee), Daucus carota (carrot), Lippia sp. (lemongrass), Matricaria chamomilla (chamomile), Mentha piperita (mint), Ocimum basilicum (basil), Olea europaea (olive), Origanum vulgare (oregano), Saccharum sp. (sugar cane) and Zingiber officinale (ginger). Nineteen scientific publications were obtained and the information synthesized was used to elaborate pre-test questionnaires, applied before the execution of a dynamic class, and post-test. The students demonstrated to know all the plants as medicinal both in the pre-test, in low percentage, and in the post-test. Most of the students know more than one medicinal plant and information about the plants was obtained verbally through family members (58\%), teachers (58\%), health workers (41\%) and friends (21\%). The use of these plants was mainly through tea (93\%), consumption (43\%) and inhalation (21\%), for the treatment of influenza (86\%), fever (71\%), inflammations (57\%), headache (50\%), injuries and insomnia (43\%). Of course, the 14 mentioned species are part of the socio-historical and cultural context of the high school students of a high school in João Pessoa, and were used as herbal medicine through information obtained through popular knowledge through the verbal transmission of information to combat various symptoms. It can also be emphasized that the use of the dynamic class and the method was effective both for interaction and dialogue between student-student and student-teacher and in the increase of students' understanding.

Keywords: Environmental education; Medicinal plants; Formal education; Ethnobotany.

\section{Introdução}

O Brasil é um dos países mais rico em biodiversidade, que ainda está sendo reconhecida, entretanto boa parte desta riqueza está sendo perdida, ameaçada por ações antrópicas (Dias, 2015). As experiências com a biodiversidade acumulam informações associadas ao senso comum, geralmente transmitidas oralmente de geração para geração, como também ao conhecimento científico (Borba e Macedo, 2006; Badke et al., 2012; Santos et al., 2015).

Cerca de $80 \%$ da população mundial vive em áreas rurais e dependem principalmente da medicina tradicional para tratamentos e prevenção de doenças, apesar de algumas propriedades e componentes destas plantas estarem ocultos ou em fase de teste científico. O uso tradicional de plantas está presente em relatos antigos desde 4500-1600 A.C. Na cultura Hindu e em outras culturas, entre os usos a fitoterapia exibe um grande potencial no tratamento de doenças e no desenvolvimento de pesquisas científicas (Maciel et al., 2002; Joshi et al., 2009; Silva et al., 2010; Santos et al., 2015).

A etnobotânica é a relação do conhecimento cultural de plantas obtidos por experiências antrópicas acumuladas 
como informações nas sociedades ao longo do contexto histórico-evolutivo. Dentre estas informações estão presentes as propriedades medicinais de espécies vegetais, utilizadas na cultura e pesquisas, principalmente associadas aos efeitos farmacológicos e tratamentos (Araújo, 2007; Dias, 2015; Santos et al., 2015).

A educação ambiental consiste em um instrumento de ação educativo, dinâmico e dialético que visa a desenvolver a consciência da realidade humana e social voltados para conservação e preservação da natureza como recurso natural altamente valioso (Luck, 2003; Miranda et al., 2017).

Portanto esta pesquisa tem como objetivo identificar e integrar o conhecimento popular e científico de estudantes do primeiro ano do Ensino Médio sobre 14 espécies de plantas e suas propriedades farmacológicas obtidas através de um levantamento bibliográfico.

\section{Materiais e métodos}

\section{Coleta de dados}

$\mathrm{O}$ presente estudo foi baseado em um levantamento bibliográfico de publicações entre os anos de 2000 até 2017 sobre as propriedades medicinais de Alliums sativum (alho), Cinnamomum cassia (canela), Cymbopogon citratus (capim-santo), Cocos nucifera (сосо), Coffea arabica (café), Daucus carota (cenoura), Lippia sp. (erva-cidreira), Matricaria chamomilla (camomila); Mentha piperita (hortelã), Ocimum basilicum (manjericão), Olea europaea (azeitona), Origanum vulgare (orégano), Saccharum sp. (cana-de-açúcar) e Zingiber officinale (gengibre). A partir destas informações foram elaboradas aulas expositivas e dinâmicas numa turma do primeiro ano de uma escola pública no Município de João Pessoa.

\section{Questionários experimentais}

No primeiro momento foi realizada uma avaliação quali-quantitativa dos conhecimentos dos estudantes, utilizando questionários pré-teste e pós-teste para verificar os saberes dos alunos baseados nas seguintes perguntas ((Bervian e Cervo,
2002; Dias, 2015): 1- Quais plantas medicinais os alunos conhecem? 2- Quantas plantas medicinais os alunos conhecem? 3- Como os alunos obtiveram o saber prévio sobre plantas medicinais (verbalmente ou escrito)? 4- Quem transmitiu as informações da planta medicinal e o seu uso? 5- Como os alunos utilizaram as plantas medicinais? 6- Quantos alunos já utilizam plantas com o intuito de tratar alguma doença? 7- Quais as doenças que os alunos trataram com estas plantas?

O teste estatístico qui quadrado $\left(\mathrm{X}^{2}\right)$ com correção em Yates foi utilizado para comparar e verificar se existe uma diferença diferente do acaso para o pré-teste e pós-teste.

\section{Aula expositiva e dinâmica}

Posterior à aplicação do pré-teste foi executada na sala de aula o jogo "Quem sou eu?”, no qual foram utilizadas palavras associadas aos tratamentos, microrganismos, plantas medicinais, doenças e sintomas. Estas palavras foram escritas em papéis adesivos (Post-it) que ficaram fixados nas testas dos alunos, de modo que estes não pudessem visualizar as palavras escritas nos papéis colados em suas testas, e então o jogo foi iniciado. O objetivo desde jogo é que o aluno descubra qual é a palavra que está escrita no papel fixado em sua testa. Teoricamente, estes alunos precisam desenvolver um pensamento científico e lógico voltado para os objetos e fenômenos associados à fitoterapia e à saúde.

Deste modo, cada aluno pode colaborar com uma parte de seu conhecimento e expor as suas experiências culturais e sociais, como o modo que determinada planta medicinal foi utilizada e a pessoa que o ensinou sobre o seu uso, tornando a aula mais cativante e também ligada ao meio ambiente nos quais os discentes estão inseridos. Este jogo pode ser executado com as cadeiras dispostas em círculo, em um único ou em vários grupos, também é o opcional que os alunos ou o professor escrevam a palavra do papel.

Ao final do jogo foram distribuídos papéis em branco aos alunos para 
escreverem uma determinada cura para determinados problemas associados à sua percepção do mundo e seus fenômenos socioeconômicos, históricos e culturais. Cada aluno ao falar sobre sua a cura de determinada enfermidade deve descrever e discutir com os demais alunos qual foi 0 problema pensado para a cura escolhida.

\section{Resultados e discussão}

\section{Levantamento bibliográfico}

Foram obtidas 19 publicações, desde 1978 até 2017, incluindo artigos e livros, sobre as espécies de plantas objetos de estudo desta pesquisa. Na Tabela 1 são apresentadas a síntese, as referências e as informações das propriedades medicinais e farmacológicas, comprovadas cientificamente, bem como outras formas de uso tradicional das espécies pesquisadas.

O alho (Alliums sativum) contém cerca de 17 tipos de aminoácidos, uma alta concentração de 33 componentes sulfúricos considerados os principais responsáveis pelo odor forte e efeitos medicinais da planta. Além disso, possui várias enzimas, minerais, e de vitaminas A, B1 e C. Entre as propriedades medicinais comprovadas estão a inibição de bactérias e fungos, redução da pressão sanguínea, colesterol e glicogênio, e também prevenção da coagulação sanguínea (Gebreyohannes e Gebreyohannes, 2013; Schäfer e Kaschula, 2014).

Tabela 1. Síntese das espécies vegetais e efeitos farmacológicos e medicinais registrados na literatura.

\begin{tabular}{|c|c|c|c|}
\hline Espécie & Nome popular & Efeito farmacológico & Referência \\
\hline Alliums sativum & Alho & $\begin{array}{l}\text { Antibacteriana, antifúngica e } \\
\text { antiviral; redutor da pressão } \\
\text { sanguínea, colesterol e glicose; } \\
\text { componentes sulfúricos (N); } \\
\text { aminoácidos; vitaminas e minerais; } \\
\text { câncer; antioxidante; doenças } \\
\text { cardíacas; inflamações; consumido } \\
\text { naturalmente, como chá ou } \\
\text { tempero. }\end{array}$ & $\begin{array}{l}\text { Gebreyohannes } \\
\text { Gebreyohannes } \\
\text { (2013); Schäfer } \\
\text { Kaschul (2014). } \\
\end{array}$ \\
\hline Cinnamomum cassia & Canela & 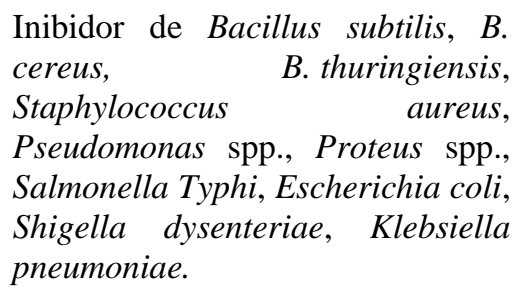 & $\begin{array}{l}\text { Chiang et al. (2005); } \\
\text { Baranauskienè, (2006); } \\
\text { Chaudhry e Tariq, } \\
\text { (2006); Joshi et al. } \\
\text { (2009). }\end{array}$ \\
\hline Cymbopogon citratus & Capim-Santo & $\begin{array}{l}\text { Popularmente é calmante; } \\
\text { antimicrobiano; antifúngico. }\end{array}$ & $\begin{array}{l}\text { Vinitketkumnuen et al. } \\
\text { (1994); Ross (2005); } \\
\text { Santos et al. (2015). }\end{array}$ \\
\hline Cocos nucifera & Coco & $\begin{array}{l}\text { Água, óleo e proteínas usados no } \\
\text { Brasil para o tratamento de diarreia } \\
\text { e artrite; cientificamente atua em } \\
\text { imunodeficiência e viroses; o } \\
\text { extrato alcoólico é analgésico; } \\
\text { anticonvulsivo e inibidor de } \\
\text { bactérias Bacillus subtilis, } \\
\text { Escherichia coli, Salmonella } \\
\text { typhosa e Staphylococcus aureus. }\end{array}$ & $\begin{array}{l}\text { Frentzel-Beyme } \\
\text { Helmert (2000); Ross } \\
(2005) \text {. } \\
\end{array}$ \\
\hline
\end{tabular}


Tabela 1. Continuação.

\begin{tabular}{|c|c|c|c|}
\hline Espécie & Nome popular & Efeito farmacológico & Referência \\
\hline Coffea arabica & Café & $\begin{array}{l}\text { No Brasil usado para o tratamento } \\
\text { de gripe cânceres e adenomas na } \\
\text { tireoide; consumido como chá de } \\
\text { suas sementes trituradas; extrato de } \\
\text { sementes verdes anti-inflamatórias; } \\
\text { antiviral. }\end{array}$ & $\begin{array}{l}\text { Schoroeder (1978); } \\
\text { Knowalchuk (1978); } \\
\text { Frentzel-Beyme e } \\
\text { Helmert (2000); Ross } \\
\text { (2005). }\end{array}$ \\
\hline Daucus carota & Cenoura & $\begin{array}{l}\text { Extrato aquoso da raiz seca atua } \\
\text { como tônico e um estimulante } \\
\text { redutor de diabetes; antibacteriano; } \\
\text { Entamoebar histolytica, } \\
\text { Streptococcus beta hemolytica e } \\
\text { Staphylococcus. }\end{array}$ & $\begin{array}{l}\text { De Blasi et al. (1990); } \\
\text { Kilibarda et al. (1996) } \\
\text { e Avallone et al. } \\
(2000) \text {. }\end{array}$ \\
\hline Lippia sp. & Erva-Cidreira & $\begin{array}{l}\text { Popularmente para o trato } \\
\text { respiratório e digestório; anti-fungo } \\
\text { Candida albicans; atua contra } \\
\text { Salmonella e tumores; melhora a } \\
\text { qualidade de vida e sistema imune. }\end{array}$ & $\begin{array}{l}\text { Duarte et al. (2015); } \\
\text { Santos et al. (2015). }\end{array}$ \\
\hline Matricaria chamomilla & Camomila & $\begin{array}{l}\text { Chás de flores secas são usados } \\
\text { como calmante; flavonoides } \\
\text { isolados; Inibidor de receptores } \\
\text { acetil-CoA; convulsões e } \\
\text { espasmos; atividade locomotora } \\
\text { reduzida em ratos. }\end{array}$ & Ross (2005). \\
\hline Mentha piperita & Hortelã & $\begin{array}{l}\text { Popularmente é calmante; } \\
\text { antiasmáticas; antimicrobianas; } \\
\text { antifungicas; Candida albicans. }\end{array}$ & $\begin{array}{l}\text { Ross (2005); Santos et } \\
\text { al. (2015). }\end{array}$ \\
\hline Ocimum basilicum & Manjericão & $\begin{array}{l}\text { Apenas bactérias do gênero } \\
\text { Bacillus e Staphylococcus; } \\
\text { atividade antiviral. }\end{array}$ & $\begin{array}{l}\text { Chiang et al. (2005); } \\
\text { Baranauskienè (2006); } \\
\text { Chaudhry e Tariq, } \\
\text { (2006); Joshi et al. } \\
\text { (2009). }\end{array}$ \\
\hline Olea europaea & Azeitona & $\begin{array}{l}\text { Chá das folhas para diurese, } \\
\text { hipertensão e diabetes; inibição de } \\
\text { bactérias Pseudomonas aeruginosa } \\
\text { e Salmonella typhi e fungo } \\
\text { Candida albicans. }\end{array}$ & $\begin{array}{l}\text { Guerin; Reveillere } \\
\text { (1985); Alkofahi et al. } \\
\text { (1997); Ross (2005) }\end{array}$ \\
\hline Origanum vulgare & Orégano & $\begin{array}{l}\text { Inibidor de S. aureus, B. subtilis, } \\
\begin{array}{l}\text { E. coli, } \\
\text { K. pneumoniae e S. typhi. }\end{array}\end{array}$ & $\begin{array}{l}\text { Chiang et al. (2005); } \\
\text { Baranauskienè (2006); } \\
\text { Chaudhry e Tariq } \\
\text { (2006); Joshi et al. } \\
(2009) \text {. }\end{array}$ \\
\hline Saccharum sp. & Cana-de-açúcar & $\begin{array}{l}\text { No Brasil usado para o tratamento } \\
\text { de hipertensão e diabetes; bagaços } \\
\text { usados para a cicatrização de } \\
\text { queimaduras e ferimentos; experi- } \\
\text { mentalmente antibacteriano (caldo } \\
\text { de cana); extrato alcoólico da folha } \\
\text { (95\%) anti-hiperglicêmico. }\end{array}$ & Ross (2005). \\
\hline
\end{tabular}


Tabela 1. Continuação.

\begin{tabular}{|c|c|c|c|}
\hline Espécie & Nome popular & Efeito farmacológico & Referência \\
\hline Zingiber officinale & Gengibre & $\begin{array}{l}\text { Chá das raízes para bronquite, } \\
\text { gripe e reumatismo; demonstraram } \\
\text { efetividade como antialérgico, } \\
\text { anticonvulsionante; diminui o } \\
\text { LDL; antiasmático } \\
\text { antimicrobiano. }\end{array}$ & Ross (2005). \\
\hline
\end{tabular}

$\mathrm{O}$ alho ainda pode estimular o sistema imune, estimulando a remoção de produtos resíduos no sistema linfático, atua também como antioxidante consequentemente anticancerígeno, por previr a ação de radicais livres nas células. Além disso evita doenças cardíacas e infecções virais. Os componentes isolados somam cerca de 200 substâncias que atuam em várias patologias humanas ainda sob investigação (Gebreyohannes e Gebreyohannes, 2013; Schäfer e Kaschula, 2014). Tradicionalmente, no nordeste do Brasil os bulbos do alho são consumidos como tempero, em chás, podendo ser também ingerido após o fracionamento junto com água, ou mastigado com banana.

O coco (Cocos nucifera) é utilizado tradicionalmente no Brasil para o tratamento de diarreia e artrite, o extrato de seu óleo e uma proteína, chamada monolaurina, são utilizados no tratamento de imunodeficiência e viroses (Ross, 2005). Além disso, experimentos com o extrato alcoólico demonstram propriedades analgésicas e anticonvulsivo em camundongos, bem como ação inibitória de bactérias Bacillus subtilis, Escherichia coli, Salmonella typhosa, Staphylococcus aureus e fungos (Ross, 2005).

No Brasil, popularmente o café (Coffea arabica) tem suas sementes secas consumidas oralmente para atuar contra efeitos da gripe. Extratos das sementes verdes administradas em adultos com inflamações na pele demonstraram uma melhora na cicatrização, já os grãos secos em extratos líquidos possuem atividade contra tumores mamários em camundongos (Schoroeder, 1978). Além disso, a bebida quente diminui a atividade de poliovírus (Knowalchuk, 1978). Foi testado e confirmado em um estudo na Alemanha que o consumo de café e de vegetais folheáveis da Família Brassicaceae (brocólis e couve-flor) pode atuar fortemente contra 0 aumento de cânceres e adenomas na tireoide (Frentzel-Beyme e Helmert, 2000; Ross, 2005).

A cenoura (Daucus carota) tem sido utilizada na cultura popular brasileira como tônico e redutor de diabetes, em forma de extrato com a água de sua raiz seca (Ross, 2005). O uso farmacológico de seu óleo essencial demonstrou uma atividade contra bactérias, como Streptococcus beta hemolytic e Staphylococcus aureus, bem como contra o protozoário Entamoeba histolytica (De Blasi et al., 1990; Kilibarda et al., 1996; Ross, 2005).

São utilizados popularmente os chás das folhas de azeitonas (Olea europaea) para o tratamento de hipertensões e indução de diurese (Ross, 2005). Experimentos comprovam a inibição de bactérias, como Pseudomonas aeruginosa e Salmonella typhi (Perez e Anesini, 1994). Os extratos alcoólicos (50\%) possuem atividade contra infecções causadas por fungos (Guerin e Reveillere, 1985; Alkofahi et al., 1997; Ross, 2005). Já a cana-de-açúcar (Saccharum sp.) é utilizada para tratamentos de hipertensão e diabetes, como também seus bagaços são aproveitados para cicatrização de queimaduras e ferimentos cutâneos. O extrato do caule possuem propriedades farmacológicas antibacterianas,o álcool (95\%) feito com as folhas possui propriedades anti-hiperglicemia em experimentos com coelhos (Ross, 2005).

A erva-cidreira (Lippia sp.) possui o maior número de citações de usos 
medicinais registrados, cerca de 85 publicações de um total 55 espécies de plantas analisadas por Santos et al. (2015). Os tratamentos mais comuns envolvem o trato respiratório e digestório. Duarte et al. (2005) encontraram uma alta atividade do óleo essencial contra o fungo Candida albicans, causador da candidíase, tanto para a erva-cidreira quanto para o hortelã (Mentha spp.) e o capim-santo (Cymbopogon spp.). Além disso o capimsanto atua como inibidor de salmonela e evita o crescimento de tumores em ratos com fibrosarcoma. O chá de capim-santo farmacologicamente não é tóxico e seus componentes podem melhorar a qualidade de vida, devido à sua atuação cooperativa ao sistema imune e atividades antivirais (Vinitketkumnuen et al., 1994; Ross, 2005). Joshi et al. (2009) utilizaram o conhecimento etnobotânico de comunidades asiáticas para testar o uso da canela (Cinnamomum cassia), do manjericão (Ocimum basilicum) e do orégano (Origanum vulgare) em um experimento com bactérias medicinalmente importantes, Bacillus subtilis, Bacillus cereus, Bacillus thuringiensis, Staphylococcus aureus, Pseudomonas spp., Proteus spp., Salmonella typhi, Escherichia coli, Shigella dysenteriae, Klebsiella pneumoniae.

Foram confirmadas a atividade antibacteriana dos extratos canela para todas bactérias, exceto para S. typhi. O extrato de orégano inibiu $S$. aureus, $B$. subtilis, E. coli, $S$. dysenteriae, $K$. pneumoniae e $S$. typhi. Enquanto que o manjericão apenas surtiu efeito sobre bactérias do gênero Bacillus $e$ Staphylococcus, entretanto outros estudos mostram atividades de substâncias isoladas do manjericão contra vírus e suas respectivas infecções (Chiang et al., 2005; Baranauskienè, 2006; Chaudhry e Tariq, 2006; Joshi et al., 2009).

As flores secas da camomila (Matricaria chamomilla) são utilizadas frequentemente como calmante no Brasil e em outras partes do mundo. Para a confirmação de seu efeito medicinal foram isolados flavonoides da espécie e testados em células granuladas cerebelares. Uma de suas proteínas, a Apigenina, inibiu a região do receptor indutor de convulsões e espasmos (Acetil-CoA). E reduziu a atividade locomotora em ratos, demonstrando uma possível atividade sedativa dessa planta (Avallone et al., 2000).

O chá das raízes de gengibre (Zingiber officinale) é utilizado no Brasil para o tratamento de bronquite, gripe e reumatismo. Alguns testes com doses do chá demonstram ação antialérgica e anticonvulsionante, diminuição na quantidade de gordura (LDL) nas artérias. Como também propriedades antiasmáticas e antimicrobianas (Ross, 2005). Portanto a partir das informações adquiridas pode-se afirmar que todas as quatorze espécies de plantas utilizadas neste estudo e que estão inclusas no cotidiano brasileiro possuem de modo geral algum tipo propriedade benéfica e maléfica aos seres humanos e outros organismos. Entretanto a o mecanismo de ação fitoterápica depende de um limiar de concentração do uso de substâncias como também outros componentes que podem ser utilizados em associação ou isoladamente.

\section{Questionários experimentais}

Anterior ao início da exposição das informações e da dinâmica do "Quem sou eu?” aos alunos do ensino médio do primeiro ano foram aplicados os questionários pré-testes. Foram avaliados 14 alunos numa faixa-etária entre os 15 e 18 anos, que pertenciam ao primeiro ano do ensino médio de um colégio da rede pública no Município de João Pessoa.

Após a aplicação do questionário pré-teste foi aplicada a dinâmica e posteriormente apresentadas as propriedades medicinais das plantas utilizadas no estudo, além da abordagem descrita pelo levantamento bibliográfico foram ouvidos como os alunos utilizavam as plantas, as experiências acumuladas ao longo de sua vida com os objetos de estudos. Pode-se observar que após a aplicação da dinâmica os alunos obtiveram uma maior compreensão das plantas medicinais como um todo (Figura 1). 


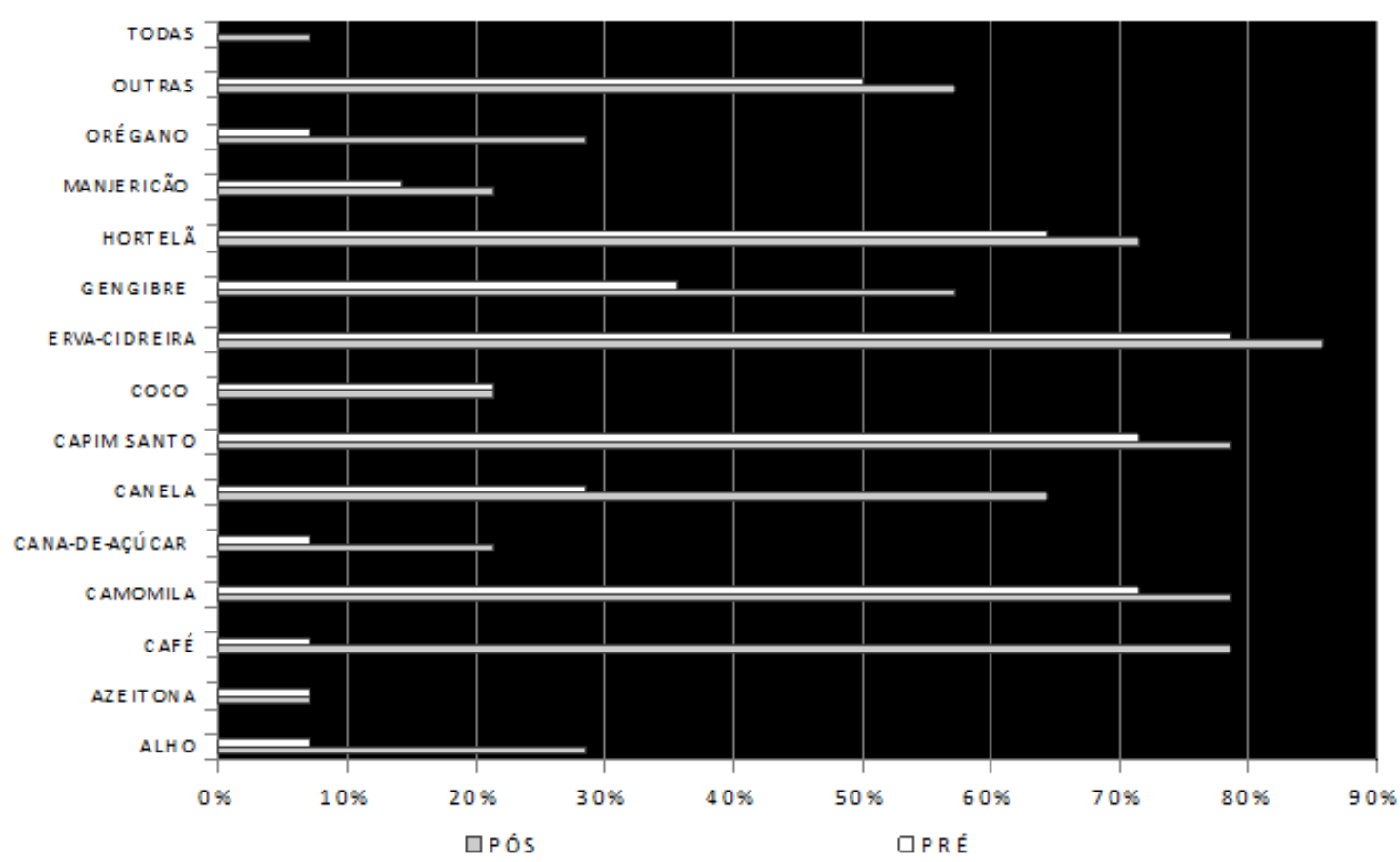

Figura 1. Percentual de plantas consideradas medicinais pelos alunos durante o pré-teste e o pós-teste.

O café foi a espécie que mais apresentou mudanças na perspectiva dos alunos que no pré-teste apenas atingiu 7\% como planta medicinal e no pós-teste chegou a $78 \%$, possivelmente demonstrando uma considerável ampliação do conhecimentos e dos efeitos que são considerados farmacológicos, tendo em vista que o café também é um estimulante energético. $\mathrm{O}$ mesmo ocorreu com $\mathrm{O}$ orégano e a cana-de-açúcar, ambos eram apenas considerados por $7 \%$ da turma como fitoterápico, porém no pós-teste o orégano saltou para $28 \%$ e a cana-de-açúcar para $21 \%$.

A opção de outras plantas medicinais, em que os alunos poderiam escrever individualmente quais seriam outras plantas conhecidas pelos indivíduos que não constavam no questionário, foram preenchidas em sua maioria, a maconha, reconhecidas a nível de gênero (Cannabis) pelos discentes.

Após a aplicação da dinâmica também foi observado um aumento considerável no número de plantas medicinais conhecidas pelos alunos (Figura 2). A maioria dos alunos, cerca de $78 \%$ no pré-teste e $100 \%$ no pós-teste, obtiveram informações sobre as plantas verbalmente (Figura 3), demonstrando assim a importância do conhecimento popular e do valor cultural associado a fitoterapia.

Outro dado bastante interessante é que a maioria desses conhecimentos sobre plantas medicinais foram adquiridos pelos alunos através de familiares, professores e agentes de saúde, respectivamente, tanto no pré-teste quanto no pós-teste (Figura 4). O modo de consumo majoritário foi como chá (93\%) tanto no pré e pós-teste, seguido de consumo (43\%) e inalação (21\%). Pode-se destacar também o aumento do tratamento através do consumo das espécies vegetais que no pré-teste era de $7 \%$ e no pós-teste subiu para 43\%, outro aumento foi encontrado na inalação que no pré-teste se apresentava em $14 \%$ e aumentou posteriormente para 21\% (Figura 5). 


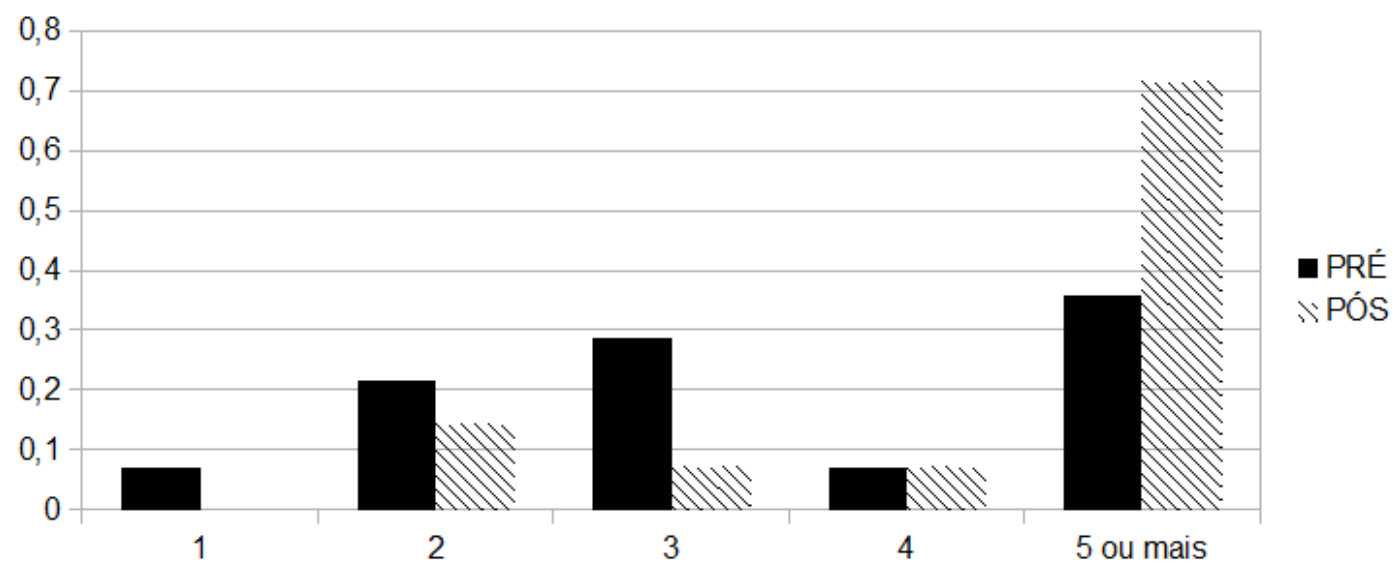

Figura 2. Número de plantas medicinais conhecidas pelos alunos durante o pré-teste e o pós-teste.

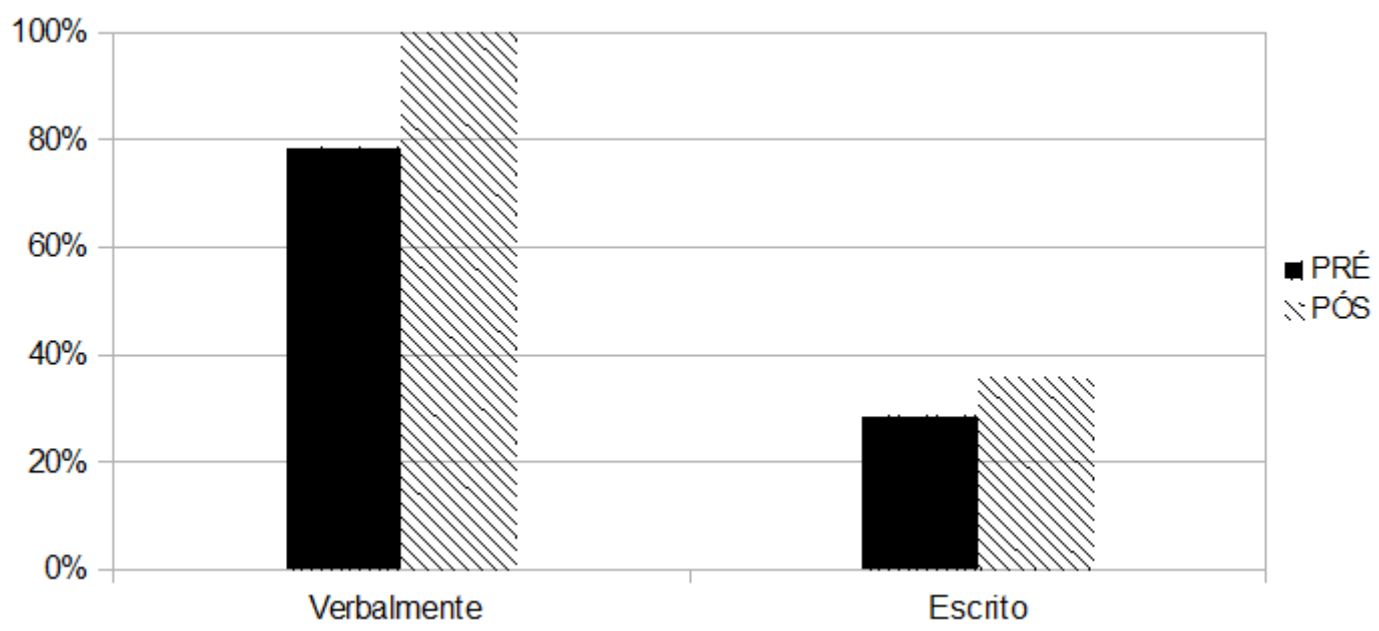

Figura 3. Modo como os alunos adquiriram informações sobre as plantas medicinais durante o pré-teste e o pós-teste.

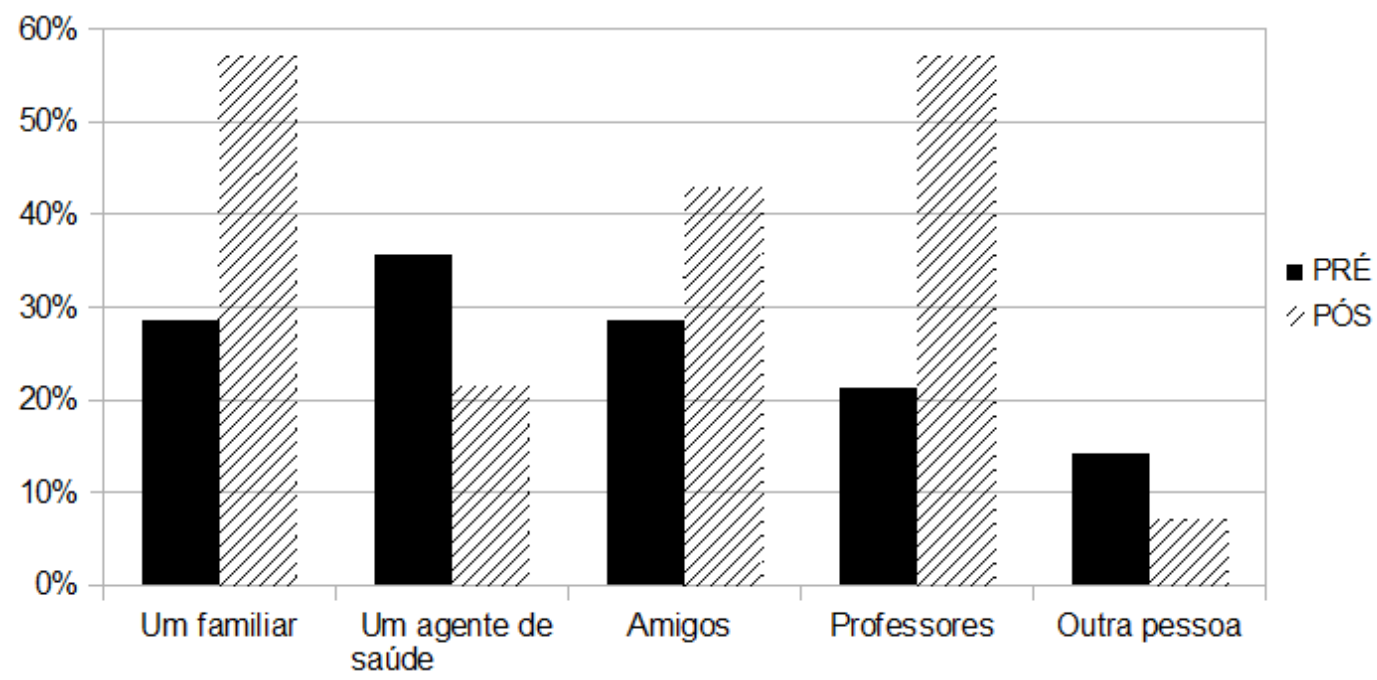

Figura 4. Pessoas que transmitiram as informações para os alunos sobre as plantas medicinais durante o pré-teste e o pós-teste. 


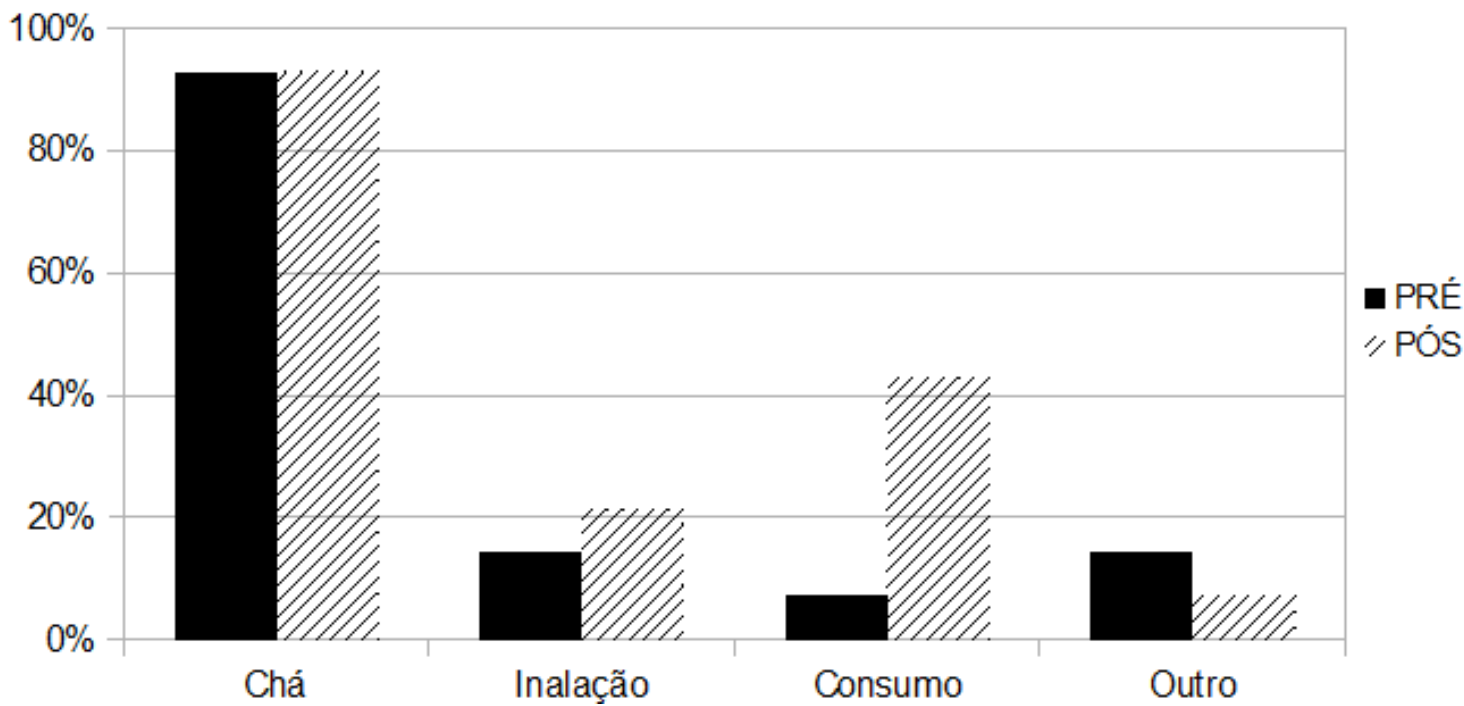

Figura 5. Modo de utilização das plantas medicinais pelos alunos durante o pré-teste e o pós-teste.

Os alunos reconhecem propriedades medicinais ou farmacológicas em todas as plantas apresentadas nos questionários pré e pós-teste. Apesar de todas as plantas apresentadas serem utilizadas medicinalmente em algumas culturas e farmacologicamente, apenas um aluno marcou todas as alternativas, exceto a azeitona que não apresentou diferença no pós-teste (Figura 6).

No pré-teste as doenças mais tratadas pelos alunos foram, respectivamente: gripe (71\%); febre (36\%); dor de cabeça e insônia, ambas com 29\%. Entretanto durante o pós-teste houve um aumento no tratamento de gripe (86\%); febre (71\%); inflamações (57\%); dor de cabeça (50\%); ferimentos e insônia, ambos com 43\% (Figura 7). Este aumento possivelmente demonstra um aumento na compreensão do uso da fitoterapia durante as experiências em que os alunos estiveram doentes, a maioria destes alunos relatou que esses tratamentos foram dosados e introduzidos por familiares que cuidavam dos indivíduos.

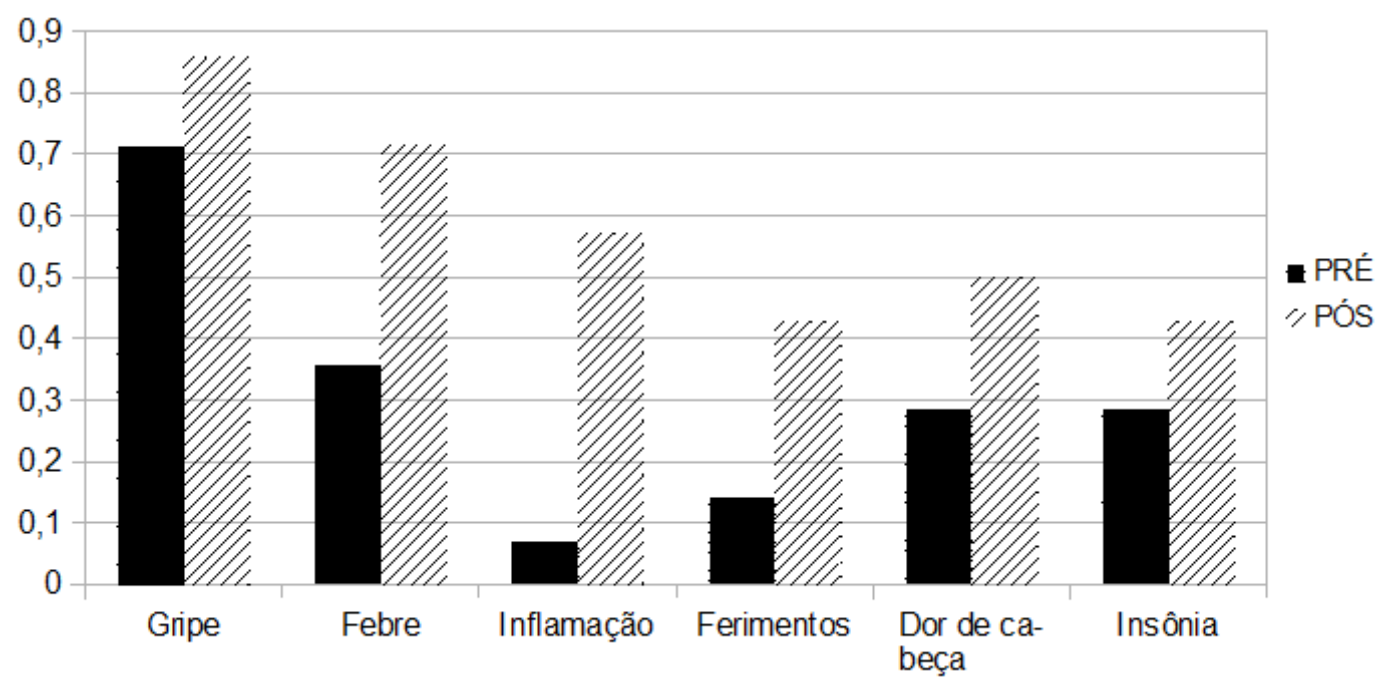

Figura 6. Percentual de doenças tratadas com plantas pelos alunos através durante o pré-teste e o pósteste. 


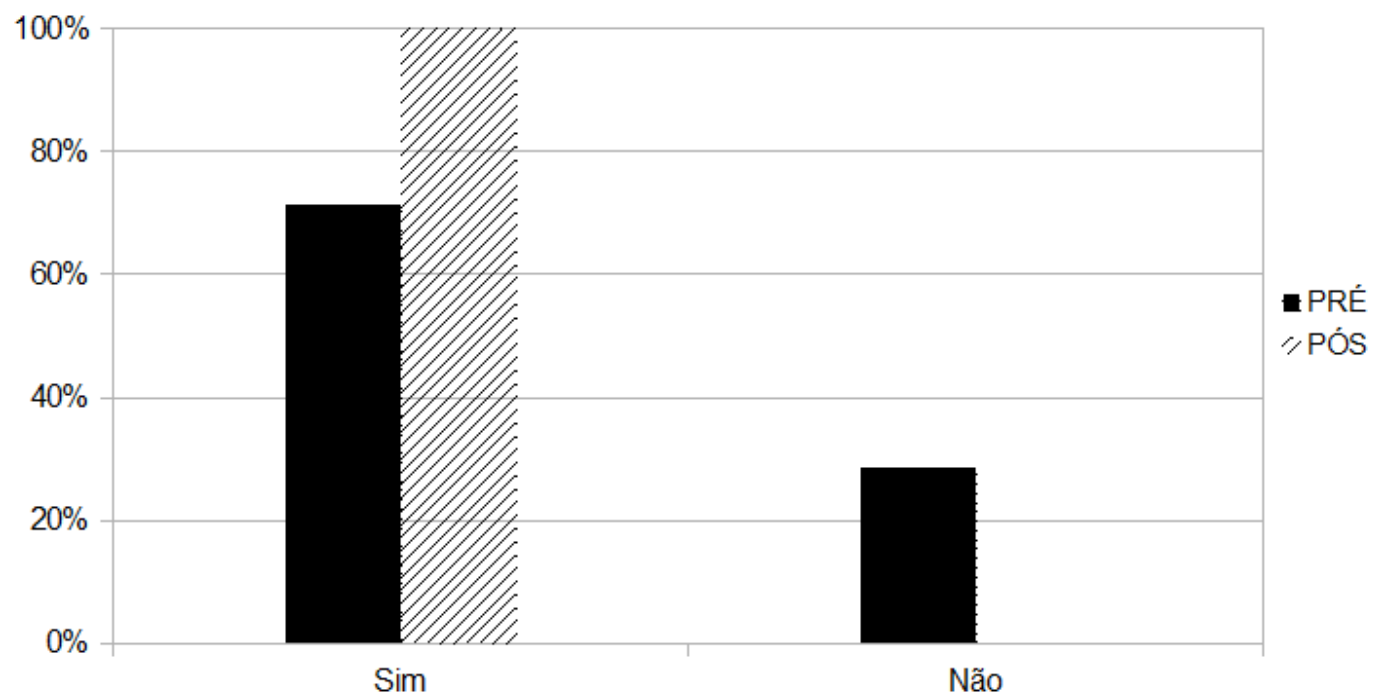

Figura 7. Percentual de alunos que utilizaram plantas como tratamento medicinal durante o pré-teste e o pós-teste.

Todos os alunos utilizaram as plantas para tratar algum tipo de doença (100\%), porém esse percentual apenas foi atingido no pós-teste, provavelmente porque os alunos não tinham conhecimento das propriedades medicinais das espécies vegetais usadas por eles ou devido a falta de atenção durante a fase de preenchimento do pré-teste (Figura 7). Todos os testes estatísticos foram insignificantes provavelmente devido à baixa amostragem de alunos.

\section{Conclusão}

Portanto pode-se afirmar que todas as 14 espécies estudadas fazem parte do contexto sócio-histórico e cultural dos estudantes do primeiro ano do Ensino Médio de um colégio em João Pessoa, e que essas plantas foram utilizadas com intuito de tratamentos fitoterápicos obtidos majoritariamente através do conhecimento popular pela transmissão verbal da informação, usadas principalmente como chá para combater diversos sintomas. Também se pode enfatizar que o uso da aula dinâmica e do método foi eficaz para realização da interação e diálogo entre aluno-aluno e aluno-professor, como também foi efetivo no aumento da compreensão dos estudantes.

\section{Declaração de conflito de interesses}

O autor declara não haver conflito de interesses.

\section{Referências}

Alkofahi, A.; Batshoun, R.; Owais, W.; Najib, N. Biological activity of some Jordanian medicinal plant extracts. Fitoterapia, v. 68, n. 2, p. 163-168, 1997.

Araújo, L. G. Etnobotânica caiçara: diversidade e conhecimento de recursos vegetais no litoral paulista. Campinas: Universidade Estadual de Campinas,. 2007. (Dissertação de mestrado).

Avallone, R.; Zanoli, P.; Puia, G.; Kleinschnitz, M.; Schreier, P.; Baraldi, M. Pharmacological profile of apigenin, a flavonoid isolated from Matricaria chamomilla. Biochemical Pharmacology, v. 59, n. 11, p. 1387-1394, $2000 . \quad$ https://doi.org/10.1016/S00062952(00)00264-1

Badke, M. R.; Budó, M. L. D.; Alvim, N. A. T.; Zanetti, G. D.; Heisler, E. V. Saberes e práticas populares de cuidado em saúde com o uso de plantas medicinais. Texto \& Contexto Enfermagem, v. 21, n. 2, p. 363-370, 2012. https://doi.org/10.1590/S010407072012000200014

Baranauskienė, R.; Venskutonis, P. R.; Dewettinck, K.; Verhe, R. Properties of oregano (Origanum vulgare L.), citronella (Cymbopogon nardus G.) and marjoram (Majorana hortensis 
L.) flavors encapsulated into milk protein-based matrices. Food Research International, v. 39, n. 4, p. 413-425, 2006. https://doi.org/10.1016/ j.foodres.2005.09.005

Bervian, P. A.; Cervo, A. L.; Silva, R. Metodologia científica. São Paulo: Pretence Hall, 2002.

Borba, A. M.; Macedo, M. Plantas medicinais usadas para a saúde bucal pela comunidade do bairro Santa Cruz dos Guimarães, MT, Brasil.

Acta Botanica Brasilica, v. 20, n. 4, p. 771782, 2006. https://doi.org/10.1590/S010233062006000400003

Chaudhry, N. M. A.; Tariq, P. Anti-microbial activity of Cinnamomum cassia against diverse microbial flora with its nutritional and medicinal impacts. Pakistan Journal of Botany, v. 38, p. 169, 2006. Disponível em: <http://www.pakbs.org/pjbot/PDFs/38(1)/PJB38 (1)169.pdf> . Acesso em: 23 abr. 2017.

Chiang, L.-C.; Ng, L.-T.; Cheng, P.-W.; Chiang, W.; Lin, C.-C. Antiviral activities of extracts and selected pure constituents of Ocimum basilicum. Clinical and Experimental Pharmacology and Physiology, v. 32, n. 10, p. 811-816, 2005. https://doi.org/10.1111/j.14401681.2005.04270.x

Miranda, F. H. F.; Miranda, J. A.; Ravaglia, R. Abordagem Interdisciplinar em Educação Ambiental. Revista Práxis, v. 2, p. 11-16, 2017. Disponível em: <http://revistas.unifoa.edu.br/ index.php/praxis/article/view/922/972>. Acesso em: 23 abr. 2017.

De Blasi, V.; Debrot S.; Menoud P. A.; Gendre L.; Schowing J. Amoebicidal effect of essential oils in vitro. Journal de Toxicologie Clinique et Experimentale, v. 10, n. 6, p. 361-373, 1990.

Dias, G. F. Atividades interdisciplinares de educação ambiental. São Paulo: Global, 2015.

Duarte, M. C.; Figueira, G. M.; Sartoratto, A.; Rehder, V. L.; Delarmelina, C. Anti-Candida activity of Brazilian medicinal plants. Journal of Ethnopharmacology, v. 97, n. 2, p. 305-311, 2005. https://doi.org/10.1016/j.jep.2004.11.016

Frentzel-Beyme, R.; Helmert, U. Association between malignant tumors of the thyroid gland and exposure to environmental protective and risk factors. Environmental Health, v. 15, n. 3, p. 337-358, 2000. https://doi.org/10.1515/ REVEH.2000.15.3.337

Gebreyohannes, G.; Gebreyohannes, M. Medicinal values of garlic: a review. International Journal of Medicine and Medical Sciences, v. 5, n. 9, p. 401-408, 2013. https://doi.org/10.5897/IJMMS2013.0960
Guerin, J. C.; Reveillere, H. P. Antifungal activity of plant extracts used in therapy. II. Study of 40 plant extracts against 9 fungi species. Annales de Pharmacie française, v. 43, n. 1, p. 77-81, 1985.

Joshi, B.; Lekhak, S.; Sharma, A. Antibacterial property of different medicinal plants: Ocimum sanctum, Cinnamomum zeylanicum, Xanthoxylum armatum and Origanum majorana. Kathmandu University Journal of Science, Engineering and Technology, v. 5, n. 1, p. 143-150, 2009. https://doi.org/10.3126/ kuset.v5i1.2854

Kilibarda, V.; Nanusević, N.; Dogović, N.; Ivanić, R.; Savin, K. Content of the essential oil of the carrot and its antibacterial activity. Pharmazie, v. 51, n. 10, p. 777-778, 1996.

Konowalchuk, J.; Speirs, J. I. Anti-viral effect of commercial juices and beverages. Applied and Environmental Microbiology, v. 35, p. 1219-1220, 1978. Disponível em: $<$ https://www.ncbi.nlm.nih.gov/pmc/articles/PM C243010/pdf/aem00221-0237.pdf>. Acesso em: 23 abr. 2017.

Luck, H. Pedagogia interdisciplinar: fundamentos teórico-metodológicos. 11. ed. Petrópolis: Vozes, 2003.

Maciel, M.A.M.; Pinto, A. C. ; Veiga Jr., V. F.; Grynberg, N. F.; Echevarria, A. Plantas medicinais: a necessidade de estudos multidisciplinares. Química Nova, v. 25, n. 3, p. 429-438, 2002. https://doi.org/10.1590/ S0100-40422002000300016

Perez, C.; Anesini, C. In vitro anti-bacterial activity of Argentine folk medicinal plants against Salmonella typhi. Journal of Ethnopharmacology, v. 44, n. 1, p. 41-46, $1994 . \quad$ https://doi.org/10.1016/03788741(94)90097-3

Ross, I. A. Medicinal plants of the world: chemical constituents, traditional and modern medicinal uses. Nova York, 2005. v. 3. https://doi.org/10.1007/978-1-59259-887-8

Santos, A. C. B.; Nunes, T. S.; Coutinho, T. S.; Silva, M. A. P. Uso popular de espécies medicinais da Família Verbenaceae no Brasil. Revista Brasileira de Plantas Medicinais, v. 17, n. 4, supl. 2, p. 980-991, 2015. https://doi.org/10.1590/1983-084X/14_083

Schäfer, G.; Kaschula, C. H. The immunomodulation and anti-inflammatory effects of garlic organosulfur compounds in cancer chemoprevention. Anti-Cancer Agents in Medicinal Chemistry, v. 14 , n. 2, p. 233240, 2014. https://doi.org/10.2174/18715 206113136660370 
Schroeder, E. Preliminary study of Chinese anticancer drugs. Anais Paulistas de Medicina e Cirurgia, v. 105, n. 1, p. 67-94, 1978.

Silva, M. P. L.; Guimarães, O. S.; Almassy Júnior, A. A.; Silva, F.; Martins, G. N. Levantamento etnobotânico e etnofarmacológico de plantas medicinais em comunidades rurais de Amargosa e Mutuípe-BA. Magistra, v. 22, n. 1, p. 8 -13, 2010.

Vinitketkumnuen, U.; Puatanachokchai, R.; Kongtawelert, P.; Lertprasertsuke, N.; Matsushima, T. Antimutagenicity of lemon grass (Cymbopogon citratus Stapf) to various known mutagens in Salmonella mutation assay. Mutation Research/Genetic Toxicology, $\begin{array}{llll}\text { v. } 341, & \text { n. } 1, & \text { p. } 71-75, & 1994 .\end{array}$ https://doi.org/10.1016/0165-1218(94)90025-6

Informação da Licença: Este é um artigo Open Access distribuído sob os termos da Licença Creative Commons Attribution, que permite uso irrestrito, distribuição e reprodução em qualquer meio, desde que a obra original seja devidamente citada. 